\title{
Analysis of burden of sexual assaults at Abuja: a 4-year retrospective study
}

\author{
Malachy Emeka Ayogu*, Habiba Ibrahim Abdullahi, Nathaniel D. Adewole
}

Department of Obstetrics and Gynecology, University of Abuja Teaching Hospital, Gwagwalada Abuja, Nigeria

Received: 01 December 2020

Accepted: 01 February 2021

\section{*Correspondence:}

Dr. Malachy Emeka Ayogu,

E-mail: emekamalachy01@gmail.com

Copyright: ( ) the author(s), publisher and licensee Medip Academy. This is an open-access article distributed under the terms of the Creative Commons Attribution Non-Commercial License, which permits unrestricted non-commercial use, distribution, and reproduction in any medium, provided the original work is properly cited.

\begin{abstract}
Background: Sexual assault is a worldwide crime associated with traumatic experience and largely affects women and girls. It is greatly underreported, more especially in the low income countries due to our peculiar culture.

Methods: A retrospective study of sexual assault victims managed at the Hospital from January 1, 2015 to December 31, 2018. Case notes were retrieved and relevant data extracted and analyzed.

Results: A total of 58 cases were seen and mostly involving pupils/students $44(75.9 \%)$ and singles $52(89.7 \%)$. The ages ranged from 3 to 37 years with a mean of $14.1 \pm 7.8$. The assailants were known to the victims in $63.8 \%$ of cases. Sexual assault through vaginal route was the commonest type $57(98.3 \%)$ and perpetrated by one person in majority of cases $(79.0 \%)$. Physical force (43.1\%) was major method used to subdue victims. About $60.3 \%$ of assaults occurred during the daytime and mainly occurred $(60.4 \%)$ at home/office. The time interval between assault and presentation in the hospital ranged from 6 hours to 96 hours; majority presented within 24 hours (59.6\%). Only 35 $(60.3 \%)$ reported to the police. About $48.3 \%$ received post exposure prophylaxis. About $37.7 \%$ eligible for emergency contraception received it. Only $32.8 \%$ of the victims completed 3- month follow-up.

Conclusions: Sexual assault is common in our environment with most victims being less than 14 years of age and assailants were mostly persons known to them. Some victims presented late.
\end{abstract}

Keywords: Abuja, Assailants, Sexual assaults, Victims, Violence

\section{INTRODUCTION}

Sexual assault is a common and important public health problem affecting millions of people all over the world. It is driven by many factors operating in a range of social, cultural and economic background. It is one of the most dehumanizing human crimes against women with associated adverse medical and social problems.

It has been defined as any sexual act, attempt to obtain a sexual act, unwanted sexual comments or advances, or acts to traffic, or otherwise directed, against a person's sexuality using coercion, by any person regardless of their relationship to the survivor, in any setting, including but not limited to home and work. ${ }^{1}$ This act is committed against someone without that person's consent. ${ }^{1,2}$
It entails the use of physical force, coercion, deception or threat; and/or the involvement of a victim that is asleep, unconscious, under aged, mentally incapacitated or physically impaired as a result of voluntary or involuntary alcohol or drug consumption. ${ }^{3-5}$ Coercion can cover a whole spectrum of degrees of force. Apart from physical force, it may involve psychological intimidation, blackmail or other threats- for instance, the threat of physical harm, of being dismissed from a job or of not obtaining a job that is sought. ${ }^{3,4}$

Women and girls divergently experience severely trauma from sexual violence. ${ }^{1,6}$ It is often associated with undesirable consequences and can have negative health and mental impacts. ${ }^{3}$ 
Men too, can also be victims of sexual violence. ${ }^{7}$ There has been a lot of high school males who have experienced some form of sexual violence in Addis Ababa, Ethiopia. ${ }^{7}$

Unwanted pregnancy, induced abortion, trauma of the genitalia, sexually transmitted infections, and unusual vagina discharge are often experienced by the victims of sexual assault.7 Majority of those who have suffered through sexual violence are also strongly linked to deep depressions, social distress, post-traumatic stress disorder and occasionally result in fatality either from shock, severe injury or murder by the perpetrator in an attempt to hide his identity. ${ }^{3,6,7}$

In many countries of sub-Saharan Africa, sexual violence has long been a remarkable, pressing human rights issue, and the occurrences of sexual assaults are on increasing trend. There are little or no policies on protecting their citizens from rape in many sub-Sahara Africa?

Majority of the sexual abuses continue to go unreported in societies with poorly developed social networks and intervention programs, as seen in low income countries. ${ }^{7,8}$ In Nigeria, Only 2 of 40 cases of rape in Nigeria are reported. The reasons attributed to this low level of disclosure range from shame, anxiety, or fear to the likelihood of stigma, ridicule and for reducing the chances of getting marriage if the abuse was made public and the arduous legal requirements needed to prove the cases. $^{3,9}$ Most victims of sexual assault also, do not report sexual violence to police because they are ashamed, or fear of being blamed, not believed or otherwise mistreated.

Due to fear of acquiring the social stigma that is associated with homosexual behaviour, majority of male victims of sexual assault also, are unlikely to report their incidents to authorities. ${ }^{7}$

The incidence of sexual assault is on the increase trend globally and based on World Health Organization reports, one in five women may experience sexual violence by an intimate partner and up to one-third of adolescent girls report their first sexual experience as being forced in many countries. ${ }^{1,10}$ Worldwide, available data had shown that about thirty five percent of women have experienced either physical and/or sexual intimate partner violence or non-partner sexual violence. ${ }^{3}$

In Nigeria, the reported incidence of sexual assault ranged from $13.8 \%$ among female students in Maiduguri to $15 \%$ from another study done in Ibadan. ${ }^{1,11}$ More than 683,000 adult women are raped yearly in the United States according to population-based studies. ${ }^{12}$

In the United States of America (USA), $15 \%$ of the university women have experienced a sexual assault and $34-60 \%$ have faced unwanted sexual advances. ${ }^{12}$ Over $41 \%$ of sexual violence reported in South Africa involved children under the age of 18 and it was presumed that
$25 \%$ of girls are likely to be raped before the age of $16 .^{9}$ Data from epidemiological studies show that more than half of the cases occur before the age of 18 years in USA. $^{12}$

Study done in Uganda revealed that $72 \%$ of sexual assault victims presented to hospital were aged 12 or below, while in Kenya study, $50 \%$ of the sexual assault victims were below 14 years of age. ${ }^{9}$

Similarly, in a study from Maiduguri, North-East Nigeria, a sexual assault rate of $77.7 \%$ was reported among female children workers with sexual assault being more likely in girls who were younger than 12 years. ${ }^{9}$ Sixteen percent of women reported having sex against their will in the Democratic Republic of Congo. ${ }^{13}$ This high prevalence in Nigeria has been variously attributed to the enduring culture of male dominance, female social and economic disempowerment and poor or non-prosecution of sex offenders. ${ }^{8}$

The implications of these various reports are that the adolescent and young adults are the most at-risk group of sexual violence.

A poll by the National Opinion Institute in 2014 in Nigeria showed that $31 \%$ of respondents knew a victim of child rape, while close family members, friends and neighbours were identified by over one-third of respondents as assailants. ${ }^{1}$

Another study also revealed that the majority of children and teen victims know their assailants who are mostly male and often relatives, neighbours or other trusted members of the society. ${ }^{9}$

Being married or cohabiting with a partner is the most important risk factors for women in terms of their vulnerability to sexual assault. Other factors influencing the risk of sexual violence include: having previously been raped or sexually abused; young age; poverty; consuming alcohol or drugs; involvement in sex work; becoming more educated and economically empowered, at least where sexual violence perpetrated by an intimate partner is concerned; having many sexual partners. ${ }^{14}$

A Study in United States of America found that women who were raped before age of 18 years were twice likely to be raped as adults, compared with those who were not raped as children or adolescents. ${ }^{14}$

Women are at increased risk of sexual violence as well as physical violence by an intimate partner when they become more educated and they are more empowered. ${ }^{14}$

This study, therefore, aimed to review the burden of sexual assaults cases presented at University of Abuja Teaching Hospital with specific objectives of finding the incidence, profile of the victims, clinical presentations and how age, marital status, known assailants, 
relationship with the assailants, correlated with the time of occurrence of sexual assault in Abuja.

\section{METHODS}

A retrospective study of sexual assault victims presented to the Gynecological emergency of the hospital during the period of study of January 1, 2015 to December 31, 2018 was reviewed. Relevant information on the date, time and place of alleged sexual assault, the age and occupations of the victims presenting to the center, nature of assault, number of assailant(s), orifices used, weapon/method used to over-power their victims and major injuries suffered. Information also on whether the assailant(s) are known to the victim, clinical services rendered and relationship between the perpetrator and the survivor were extracted and analyzed using SPSS software for windows version 22.0. The results were expressed in numbers; percentages and $95 \%$ confidence interval were obtained where appropriate. $\mathrm{P}$ values $<0.05$ were considered statistically significant.

\section{RESULTS}

During the study period, 2,024 patients were seen in the Gynecological Emergency Unit of the Hospital. A total of 69 were for alleged sexual assault, representing $3.4 \%$ of the total cases seen. However, only $58(84.1 \%)$ case notes were available for analysis. The 58 cases seen mostly involved pupils/students $44(75.9 \%)$ and singles 52 (89.7\%). Younger age groups $46(79.3 \%)$ less than 20 ; the ages ranged from 3 to 37 years with a mean of $14.1 \pm 7.8$ years and median age of 13.5 years were the majority of the victims (Table 1).

Table 1: The socio-demographic characteristics of the victims.

\begin{tabular}{|lll|}
\hline Characteristics & Number of patients & Percentage \\
\hline Age (years) & & 31.0 \\
\hline$<10$ & 18 & 48.3 \\
\hline $10-19$ & 28 & 15.5 \\
\hline $20-29$ & 9 & 5.2 \\
\hline $30-39$ & 3 & \\
\hline Parity & & 96.6 \\
\hline 0 & 56 & 1.7 \\
\hline 1 & 1 & 1.7 \\
\hline 4 & 1 & \\
\hline Occupation & & 5.2 \\
\hline Applicant & 3 & 1.7 \\
\hline Business woman & 1 & 5.2 \\
\hline Child & 3 & 5.2 \\
\hline Civil servant & 3 & 1.7 \\
\hline Cleaner & 1 & 1.7 \\
\hline Housewife & 1 & 1.7 \\
\hline Nurse & 1 & 1.7 \\
\hline Police officer & 1 & 75.9 \\
\hline Pupil/student & 44 & \\
\hline
\end{tabular}

The assailants were known to the victims in $63.8 \%$ of cases. The younger the victims, the more likely the assault occurred in the day time and the older she was the more likely it occurred at night; $p$ value $<0.000$. Similarly, being single was a strong risk factor for it to occur at the night; $\mathrm{p}$ value $<0.001$. Also, there was an association between knowing the assailants being in close relationship and the assault occurring in the day time; $p$ value $<0.000$ (Table 2 ).

Table 2: Age, marital status, whether assailants are known, relationship with assailants and their correlation with time of occurrence.

\begin{tabular}{|c|c|c|c|}
\hline \multirow{2}{*}{ Characteristics } & \multicolumn{2}{|c|}{ Time of occurrence } & \multirow{2}{*}{ P value } \\
\hline & Night & Day & \\
\hline \multicolumn{4}{|c|}{ Age group (years) } \\
\hline$<10$ & 0 & 18 & \multirow{4}{*}{0.000} \\
\hline $10-19$ & 11 & 17 & \\
\hline $20-29$ & 9 & 0 & \\
\hline $30-39$ & 3 & 0 & \\
\hline \multicolumn{4}{|l|}{ Marital status } \\
\hline Single & 17 & 35 & \multirow{2}{*}{0.001} \\
\hline Married & 6 & 0 & \\
\hline \multicolumn{4}{|c|}{ Known assailants } \\
\hline Yes & 5 & 32 & \multirow{2}{*}{0.000} \\
\hline No & 18 & 3 & \\
\hline \multicolumn{4}{|l|}{ Relationship } \\
\hline Friend & 4 & 9 & \multirow{4}{*}{0.029} \\
\hline Neighbour & 0 & 20 & \\
\hline Authority figure & 1 & 1 & \\
\hline Teacher & 0 & 2 & \\
\hline
\end{tabular}

*Chi square

Table 3: PEP and sexual assault complications correlated with age of the patients.

\begin{tabular}{|c|c|c|c|c|c|}
\hline \multirow[b]{2}{*}{ Characteristics } & \multicolumn{4}{|c|}{ Age grouping } & \multirow[b]{2}{*}{$\begin{array}{l}\mathbf{P} \\
\text { value* }^{*}\end{array}$} \\
\hline & $\begin{array}{l}<10 \\
\text { years }\end{array}$ & $\begin{array}{l}10-19 \\
\text { years }\end{array}$ & $\begin{array}{l}20-29 \\
\text { years }\end{array}$ & $\begin{array}{l}30-39 \\
\text { years }\end{array}$ & \\
\hline \multicolumn{6}{|l|}{ PEP } \\
\hline Yes & 6 & 12 & 7 & 3 & \multirow{2}{*}{0.040} \\
\hline No & 12 & 16 & 2 & 0 & \\
\hline \multicolumn{6}{|l|}{ Complications } \\
\hline Finger strain & 0 & 1 & 0 & 0 & \multirow{6}{*}{0.029} \\
\hline $\begin{array}{l}\text { Psychological } \\
\text { trauma }\end{array}$ & 0 & 0 & 1 & 1 & \\
\hline PTSD & 0 & 0 & 1 & 0 & \\
\hline $\begin{array}{l}\text { Urethral } \\
\text { prolapsed }\end{array}$ & 2 & 0 & 0 & 0 & \\
\hline Vaginal bruises & 2 & 0 & 0 & 0 & \\
\hline Nil & 14 & 27 & 7 & 2 & \\
\hline
\end{tabular}

*Chi square, PEP (post exposure prophylaxis)

Sexual assault through vaginal route was the commonest type $57(98.3 \%)$ and perpetrated by one person in majority of cases $(79.0 \%)$. Physical force $(43.1 \%)$ was predominant method used to subdue victims and the time 
interval between assault and presentation in the hospital ranged from 6 hours to more than 96 hours with the majority $34(58.6 \%)$ of them presenting within 24 hours. Sexual acts were mainly perpetrated at victim's home 35 $(60.3 \%)$ of the cases (Table 4$)$.

Table 4: Route of assault, assault-presentation interval, place of assault and mode of overcoming their victims.

\begin{tabular}{|lll|}
\hline Characteristics & $\begin{array}{c}\text { Number of } \\
\text { patients }\end{array}$ & Percentage \\
\hline Type of sexual assault & & \\
\hline Anal route & 1 & 1.7 \\
\hline Vaginal route & 57 & 98.3 \\
\hline Interval of assault and presentation & \\
\hline 6 hours & 4 & 6.9 \\
\hline 12 hours & 12 & 20.7 \\
\hline 24 hours & 18 & 31.0 \\
\hline 48 hours & 5 & 8.6 \\
\hline 72 hours & 6 & 10.3 \\
\hline >72 hours & 12 & 20.7 \\
\hline Place of assault & & \\
\hline Home or office & 35 & 60.3 \\
\hline Uncompleted building & 5 & 8.6 \\
\hline Street corner & 10 & 17.2 \\
\hline Friend's house & 4 & 6.9 \\
\hline Taxi or bus & 2 & 3.4 \\
\hline Hotel/guest house & 2 & 3.4 \\
\hline Method of overcoming victims & \\
\hline Physical force & 25 & 43.1 \\
\hline Use of threat or violence & 11 & 19.0 \\
\hline Deceit & 13 & 22.4 \\
\hline Drug/alcohol & 9 & 15.5 \\
\hline Total & 58 \\
\hline
\end{tabular}

Table 5: Clinical services rendered and the number of sexual assault victims that reported to the police.

\begin{tabular}{|c|c|c|c|c|}
\hline \multirow{2}{*}{\multicolumn{2}{|c|}{ HIV screening victim }} & \multicolumn{2}{|c|}{ HIV status } & \multirow{3}{*}{$\begin{array}{l}\text { Total } \\
58\end{array}$} \\
\hline & & \multirow{2}{*}{$\begin{array}{l}\text { Positive } \\
3 \\
\end{array}$} & \multirow{2}{*}{$\begin{array}{l}\text { Negative } \\
55\end{array}$} & \\
\hline HIV screening of & Yes & & & \\
\hline victim* & No & 0 & 0 & \\
\hline \multirow{2}{*}{$\begin{array}{l}\text { Hepatitis B } \\
\text { screening** }\end{array}$} & Yes & 56 & & 58 \\
\hline & No & 2 & & \\
\hline \multirow{2}{*}{ Contraception use } & Yes & 22 & & 58 \\
\hline & No & 36 & & \\
\hline \multirow{2}{*}{ Reported to police } & Yes & 35 & & 58 \\
\hline & No & 23 & & \\
\hline
\end{tabular}

About $60.3 \%$ of assaults occurred during the day time and mainly occurred $(60.4 \%)$ at home/office.; Only 35 $(60.3 \%)$ reported to the police. All the patients were screened for HIV, while 56 (96.6\%) were screened for hepatitis B and only three victims tested positive for HIV
(Table 5). Mainly older patients (48.3\%) were administered post exposure prophylaxis for HIV; p value $<0.040$. There was also, a correlation between age and complications of sexual assault with the sequelae seen more in the younger age group; $p$ value $<0.029$ (Table 3) and $37.7 \%$ eligible for emergency contraception received. However, only $32.8 \%$ of the survivors completed 3month follow up. Barely $35(60.3 \%)$ of the victims reported to the police (Table 5).

\section{DISCUSSION}

Sexual assault (SA), including rape, is a human rights violation with extensive negative health consequences. ${ }^{15}$

In this study, sexual assaults constituted $3.4 \%$ of all gynecological cases in our center. This finding is comparable to the reports made by Adeleke et al in Oshogbo and by Badejoko et al in Ile-Ife. ${ }^{6,8}$ This prevalence is, however, higher than $0.9 \%$ and $0.8 \%$ documented by Ezechi et al and Akinlusi et al respectively. ${ }^{3,4}$ On the other hand, it's much lower than what were variously reported in sub-Saharan Africa. ${ }^{16}$ As seen in this study, most reports on sexual assault did not include male victims in Nigeria unlike studies from other countries. ${ }^{17-19}$ This finding is however, in contrast with the studies done in Lagos where male were also found to be victims of sexual assaults. ${ }^{3}$ This our finding may not be unconnected with the fact that gynecological emergency unit where all our victims presented were basically meant for female patients. Nevertheless, categorical statements about prevalence of sexual assault in Nigeria cannot be made and because of existing limited data. ${ }^{20}$ Furthermore, the higher the number of the denominator used, the lower the prevalence and viceversa or may be due to actual differences across locations and/or methodological differences., ${ }^{3,4,15}$ It could also be due to stigma associated with sexual violence that prevent persons assaulted from reporting. ${ }^{3}$

In this study, younger age $(79.3 \%)$ less than 20 , with the

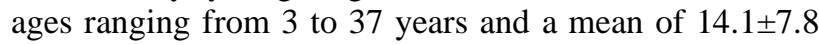
years formed the majority of the victims of the sexual assault. A similar local study by Sodipo et al in Lagos also documented that an average age of victims was 13.9 years, with children and adolescents (0-20 years) accounting for a majority of survivors. ${ }^{1}$ This study is also agreement with study by Akinlusi et al in Lagos who reported that the adolescent age group (10-19 years) accounted for the majority $(44.6 \%)$ of the cases, followed by children less than 10 years $(39.0 \%)$ and consistent with reported findings from other parts of the world that children and adolescents account for majority of sexual assault cases. ${ }^{1,3,4,12,21-23}$ Similarly, victims were mostly single and nulliparous $56(96.6 \%)$ and mainly the pupil/students $44(75.9 \%)$ and this in keeping with the observation made by Ezechi et al that sexual assault was found to be higher in teenagers and the unmarried. ${ }^{3}$ The various reasons advanced for the vulnerability of this age group include low socioeconomic status, inexperience in 
matters of sexuality. ${ }^{6}$ It has also been suggested that it may be because children are defenceless, weak to offer resistance to their assailants. ${ }^{1}$ In addition, adolescent may unknowingly engage in behaviour that exposes them to sexual assault because this period of growth is a period of experimentation and adventure. ${ }^{3}$ Thus, any intervention to reduce sexual violence against women in our environment should be channelled towards this agegroup.

The assailants were known to the victims in majority $(63.8 \%)$ of the cases. This finding correlates with another study done in South Africa that reported $67.6 \%$ of the victims knew their perpetrators. ${ }^{18}$ This finding is also in keeping with various reports from Nigeria where the majority of the perpetrators of the sexual assaults were known to the victims which could either be acquaintances (neighbours, blood relations, friends) or as authority figures and most occurring during the day and in assailants' homes/office as seen in this study. $1,3,6,12,24$ This study has demonstrated that the younger the victims, the more likely the assault occurred in the day time and the older she was the more likely it occurred at night which was statistically significant with; p value $<0.000$. Similarly, being single was a strong risk factor for it to occur in the day ( $\mathrm{p}$ value $<0.001$ ). Also, there was an association between knowing the assailants/being in close relationship (who were mainly neighbours) and the assault occurring in the day time ( $p$ value $<0.000$ ) and these findings give credence to the above statement that assailants were usually close relations who could either be co-tenants, family members or friends. It was, therefore, suggested that adolescents and teenagers should be educated on the risk associated with complete trust of persons known to them especially when such close acquaintances invite them to their homes without their guardians' or parents' knowledge. ${ }^{3}$

Sexual assault through vaginal route was the commonest type $57(98.3 \%)$ and perpetrated by one person in majority of cases $(79.0 \%)$ and physical force $(43.1 \%)$ was predominant method used to subdue victims. This finding is consistent with the work done by Nwafor and colleague who recorded penovaginal penetration in $91.8 \%$ of situations and similar to what was documented by Ezechi et al, who revealed sexual assault via vaginal $(87.2 \%)$ being the most common route. ${ }^{3}$

Sexual assault by defilement was the most common form reported in this study. This is not surprising considering the fact that the majority of the survivors were children and adolescents.

Similarly, threat of violence and physical force was the common methods for overcoming the victims as observed in this study. ${ }^{3}$ And in contrary, verbal threats was the most common means of subjugation elsewhere. ${ }^{22}$ About $11 \%$ of the victims suffered a gang rape with the assailants ranging from 2-4 and this is comparable to $6.9 \%$ recorded is Kampala, Uganda. ${ }^{21}$
This has effect of both the physical injury sustained as well as increased load of infection the victims are exposed to. ${ }^{3}$ In this study, there was a correlation between age and complications of sexual assault with more sequelae were noted in the younger age group than older victims; $\mathrm{p}$ value $<0.029$. This finding may not be unconnected with their more fragile nature of this age group.

The time interval between assault and presentation in the hospital ranged from 6 hours to more than 96 hours with the majority $34(58.6 \%)$ of them presenting within 24 hours. It can be inferred from this study that survivors presented early considering the fact that there was an ample time to prevent all forms of sexually transmitted disease as well as pregnancy from the majority of the patients. This finding is similar to what was documented in Lagos where all their patients presented within 96 hours. ${ }^{3}$ However, it is not in keeping with what was documented in Jos, Nigeria where time interval between alleged sexual assault and hospital examination of the victim varied widely, from about 4 hour to about 1 month after the incident and in Makurdi, Nigeria where only $39.1 \%$ of victims presented within 24 hours of the occurence. ${ }^{12,24}$

It was noted that cases involving younger girls keep quiet and report late to the hospital following some threatening or persuasions when compared with older girls. ${ }^{12}$ Other attributed reason is possible effect of alcohol or drugs used to overcome the victims and delay presentation to hospital. ${ }^{3}$

A lot may even go unreported for various reasons which include: victim shaming, stigma, character assassination, public backlash and limited access to justice for victims. ${ }^{25}$ Other reasons adduced for failure to report to medical services include a lack of awareness of the availability of such services, lack of knowledge of the preventability of diseases such as HIV. 3,15

Only $35(60.3 \%)$ of the victims reported to the police. This is in contrast with what was documented elsewhere where all the victims after assault reported to the police before presentation to the hospital. ${ }^{6}$ The reasons for failure to report is due to the belief that the perpetrator will not be punished and discriminatory attitudes by police and other legal officials. ${ }^{15}$ Even more worrisome is that children and adolescents would not report, unless their parents take the decision to report the incident to the police. $^{1,26}$

Health professionals have a crucial role to play in supporting the victims of sexual assault medically and psychologically and collecting evidence to assist prosecutions.

Prevention of pregnancy, treatment of complications, the administration of prophylactic antibiotics as well as 
psychological rehabilitation are hall mark of the management of sexual assault victims. ${ }^{12}$

As such, all the patients were screened for HIV, while, 56 $(96.6 \%)$ were screened for hepatitis B and only three victims tested positive for HIV. Commensurate with their time of presentation adequate care was provided for the victims. However, worrisome is that not all the victims completed their follow-up. Mainly older patients $(48.3 \%)$ were administered post exposure prophylaxis for HIV ( $\mathrm{p}$ value $<0.040$ ) unlike what was reported in Uganda where none of the victims got post exposure HIV therapy because of its non -availability in the hospital. ${ }^{21}$

The health sector is considerably more effective in countries where there are protocols and guidelines for managing cases and collecting evidence, where staff is well-trained and where there is good collaboration with the judicial system.

About 38\% eligible for emergency contraception received it. However, only $32.8 \%$ of the survivors completed 3month follow up and this contrary to what was reported elsewhere where $75.0 \%$ of the victims completed followup visits. ${ }^{3}$

The implication of this is that a good tracking system to follow up these victims should be initiated in order to assess not only the treatment success, but for emotional and psychological support as well as determination of reason for default if it occurs.

\section{CONCLUSION}

In conclusion, sexual assault is common in Abuja and the majority of the victims were minors and adolescents with persons known to them being the perpetrators in most cases. There is urgent need to sensitize the community about reporting early for medical treatment after sexual assault and Government institutions must create policies that will discourage rape and sexual violence, so as to stem the tide.

\section{Funding: No funding sources}

Conflict of interest: None declared

Ethical approval: The study was approved by the Institutional Ethics Committee

\section{REFERENCES}

1. Sodipo OO, Adedokun A, Adejumo AO, Olibamoyo O. The pattern and characteristics of sexual assault perpetrators and survivors managed at a sexual assault referral center in Lagos. Afr J Prim Health Care Fam Med. 2018;10(1):a1727.

2. Sexual violence. World Health Organization. Available from: https://www.who.int/ reproductivehealth/topics/violence/sexual_violence/e n/. Accessed on 23 October 2019.
3. Ezechi OC, Adesolamusa Z, David AK, Wapmuk AE, Gbajabiamila TA, Eugeniaidigbe I, et al. Trends and patterns of sexual assaults in Lagos southwestern Nigeria. Pan Afr Med J. 2016;24:261.

4. Akinlusi FM, Rabiu KA, Olawepo TA, Adewunmi AA, Ottun TA, Akinola OI. Sexual assault in Lagos, Nigeria: a five year retrospective review. BMC Women's Health. 2014;23(14):115.

5. Home Office. Guidance on Part 1 of the Sexual Offences Act 2003. Home Office Circular. 2004;75(2):021s.

6. Adeleke NA, Olowookere AS, Hassan MB, Komolafe JO, Asekun-Olarinmoye EO. Sexual assault against women at Osogbo southwestern Nigeria. Niger J Clin Pract. 2012;15(2):190-3.

7. Haile RT, Kebeta ND, Kassie GM. Prevalence of sexual abuse of male high school students in Addis Ababa, Ethiopia. BMC Int Health Hum Rights. 2013;13(1):1-8.

8. Badejoko OO, Anyabolu HC, Badejoko BO, Ijarotimi AO, Kuti O, Adejuyigbe EA. Sexual assault in Ile-Ife, Nigeria. Niger Med J. 2014;55:254-9.

9. Akin-Odanye EO. Prevalence and management of child sexual abuse cases presented at Nigeria hospitals: a sysmatic review. J Health Soc Sci. 2018;3(2):109-29.

10. Garcia-Moreno C, Watts C. Violence against women: an urgent public health priority. Bull World Health Organ. 2011;89:2.

11. Kullima AA, Kawuwa MB Audu BM, Mairiga AG, Bukar M. Sexual assault against female Nigerian students. Afr J Reprod Health. 2010;14(3):189-93.

12. Daru PH, Osagie EO, Pam IC, Mutihir JT, Silas OA, Ekwempu CC. Analysis of cases of rape as seen at the Jos University Teaching Hospital, Jos, North Central Nigeria. Niger J Clin Pract. 2011;14:47-51.

13. Peterman A, Palemo T, Bredenkamp C. Estimates and determinants of sexual violence against women in the Democratic Republic of Congo. Am J Public Health. 2011;101(6):1060-7.

14. Sexual violence. In: World report on violence and Health. 2002:149-181. Available from: http://www.who.int/violence_injury_prevention/viol ence/global_campaign/en/chap6.pdf. Accessed on 23 October 2019.

15. Steele SJ, Abrahams N, Duncan K, Woollett N, Hwang B, O'Connell L, et al. The epidemiology of rape and sexual violence in the platinum mining district of Rustenburg, South Africa: Prevalence, and factors associated with sexual violence. PLoS One. 2019;14(7):e0216449.

16. Folayan MO, Odetoyinbo M, Harrison A, Brown B. Rape in Nigeria: a silent epidemic among adolescents with implications for HIV infection. Glob Health Action. 2014;7:10.

17. Raj A, McDougal L. Sexual violence and rape in India. Lancet. 2014; 383(8):865.

18. Al-Azad MA, Raman Z, Ahmad M, Wahab MA, Ali M, Khalil MI. Socio-demographic characteristics of alleged sexual assault (rape) cases in Dhaka city. J 
Armed Forces Med Coll Bangladesh. 2012;7(2):21-4.

19. Jewkes R, Abrahams N. The epidemiology of rape and sexual coercion in South Africa: an overview. Soc Sci Med. 2002;55(7):1231-44.

20. Akinade E, Adewuyi T, Sulaiman A. Socio-legal factors that influence the perpetuation of rape in Nigeria. Procedia Soc Behav Sci. 2010;5:1760-4.

21. Ononge $\mathrm{S}$, Wandabwa $\mathrm{J}$, Kiondo $\mathrm{P}$, Busingye $\mathrm{R}$. Clinical presentation and management of alleged sexually assaulted females at Mulago hospital, Kampala, Uganda. Afr Health Sci. 2005;5(1):50-4.

22. Nwafor CC, Akhiwu WO. Medicolegal analysis of sexual assault victims in Benin, Nigeria. $\mathrm{N}$ Niger $\mathrm{J}$ Clin Res. 2019;8:10-7.

23. Caroline HO, Richter A. Exploring Intersections between Gender Violence; Lessons from Zimbabwe. Afr J Reprod Health. 1999;3:51-65.
24. Utoo BT, Ilora E, Utoo PM. Sexual assault reported at a law enforcement health facility in Makurdi, North-central Nigeria. J Pregnanc Reprod. 2018;2(6):5.

25. Adelodun O, Adekola T, Adekanmbi D. Statistical analysis of sampled cases of sexually assaulted female students in a Nigerian Private University. Int J Statist Appl. 2017;7(4):222-7.

26. Golan A, Dishi-Galitzky M, Barda J, Lurie S. The care of sexual assault victims: The first regional centre in Israel- 10 years' experience. IMAJ. 2012;14:658-61.

Cite this article as: Ayogu ME, Abdullahi HI, Adewole ND. Analysis of burden of sexual assaults at Abuja: a 4-year retrospective study. Int J Reprod Contracept Obstet Gynecol 2021;10:858-64. 